\title{
Active Older Adults Recollections of Childhood Foods in NZ ${ }^{+}$
}

\author{
Patricia Lucas 1,*, Carolyn Cairncross ${ }^{1}$, Phillipa Batts ${ }^{1}$, David Hoskins ${ }^{1}$, Stephen Neville ${ }^{2}$ and \\ Valerie Wright-St Clair ${ }^{2}$
}

1 School of Sport and Recreation, Auckland University of Technology, Auckland 1071, New Zealand; carolyn.cairncross@aut.ac.nz (C.C.); pbatts@aut.ac.nz (P.B.); dhoskins@aut.ac.nz (D.H.)

2 AUT Centre for Active Ageing, Auckland University of Technology, Auckland 1017, New Zealand; stephen.neville@aut.ac.nz (S.N.); Vwright@aut.ac.nz (V.W.-S.C.)

* Correspondence: patricia.lucas@aut.ac.nz; Tel.: +64-9-921-9999

+ Presented at the 2019 Annual Meeting of the Nutrition Society of New Zealand, Napier, New Zealand, 28-29 November 2019.

Published: 17 December 2019

Good health and well-being of older adults may be achieved through lifelong nutritious and satisfying food experiences. This complex area of research is multi-dimensional and interwoven with many influencers extending from childhood into adulthood. Observational and interpretive research focusing on the voices of active older adults is limited. As a platform for more extensive research, we explored what foods active older adults are consuming in New Zealand.

Qualitative descriptive methodology was utilised for this pilot study. Active older adults $(n=$ 27) aged between 67-82 years, who participate in the AUT never2old physical activity programme, were recruited from 4 sites across Auckland to contribute to a focus group $(n=4)$. Transcribed data was thematically analysed using NVivo software (QRS International Pty Ltd, Chadstone, Australia).

An interesting theme arising from the analysis was childhood food consumption. These active older adults recalled their childhood meals as quite basic and simple, with their mother central to most food preparation. Irrespective of family circumstances typical daily meals included; porridge for breakfast, sandwiches for lunch at school, and "meat and 3 veg" for dinner. Vegetables, mostly grown in the family garden, were ubiquitous. Although the availability of baking and desserts in homes were high, treats and eating out were infrequent and treasured memories. These active older adults appear to have formed "rules" for current eating patterns based on their past experiences. These rules include; seldom eating treat foods (except on special occasions), eating simply, and preferring to cook their food at home rather than eating out or using convenience foods.

Recent nutrition literature supports the link we identify between older adults current eating behaviours, and their childhood food environment and experiences. The strength of this finding lies in the food related stories and practices passed along between generations, and how these may support sustainable eating behaviours that promote physical wellness and mental wellbeing.

(C) 2019 by the authors. Licensee MDPI, Basel, Switzerland. This article is an open access article distributed under the terms and conditions of the Creative Commons Attribution (CC BY) license (http://creativecommons.org/licenses/by/4.0/). 